\title{
Auctioning Bulk Mobile Messages
}

\author{
S.Meij, L-F.Pau, E.van Heck
}

\begin{tabular}{|l|l|}
\hline \multicolumn{2}{|l|}{ ERIM REPORT SERIES RESEARCH IN MANAGEMENT } \\
\hline ERIM Report Series reference number & ERS-2003-006-LIS \\
\hline Publication & January 2003 \\
\hline Number of pages & 44 \\
\hline Email address corresponding author & Ipau@fbk.eur.nl \\
\hline Address & Erasmus Research Institute of Management (ERIM) \\
& Rotterdam School of Management / Faculteit Bedrijfskunde \\
& Rotterdam School of Economics / Faculteit Economische \\
& Wetenschappen \\
& Erasmus Universiteit Rotterdam \\
& P.O. Box 1738 \\
& 3000 DR Rotterdam, The Netherlands \\
& Phone: +31 10 408 1182 \\
& Fax: $\quad+31104089640$ \\
& Email: info@erim.eur.nl \\
& Internet: $\quad$ www.erim.eur.nl \\
\hline
\end{tabular}

Bibliographic data and classifications of all the ERIM reports are also available on the ERIM website: www.erim.eur.nl 


\title{
ERASMUS RESEARCH INSTITUTE OF MANAGEMENT
}

\author{
REPORT SERIES
}

RESEARCH IN MANAGEMENT

\begin{tabular}{|c|c|c|}
\hline \multicolumn{3}{|c|}{ BIBLIOGRAPHIC DATA AND CLASSIFICATIONS } \\
\hline Abstract & \multicolumn{2}{|c|}{$\begin{array}{l}\text { The search for enablers of continued growth of SMS traffic, as well as the take-off of the more } \\
\text { diversified MMS message contents, open up for enterprises the potential of bulk use of mobile } \\
\text { messaging, instead of essentially one-by-one use. In parallel, such enterprises or value added } \\
\text { services needing mobile messaging in bulk - for spot use or for use over a prescribed period of } \\
\text { time - want to minimize total acquisition costs, from a set of technically approved providers of } \\
\text { messaging capacity. } \\
\text { This leads naturally to the evaluation of auctioning for bulk SMS or MMS messaging capacity, } \\
\text { with the intrinsic advantages therein such as reduction in acquisition costs, allocation efficiency, } \\
\text { and optimality. The paper shows, with extensive results as evidence from simulations carried out } \\
\text { in the Rotterdam School of Management e-Auction room, how multi-attribute reverse auctions } \\
\text { perform for the enterprise-buyer, as well as for the messaging capacity-sellers. We compare 1- } \\
\text { and 5-round auctions, to show the learning effect and the benefits thereof to the various parties. } \\
\text { The sensitivity will be reported to changes in the enterprise's and the capacity providers utilities } \\
\text { and priorities between message attributes (such as price, size, security, and delivery delay). At } \\
\text { the organizational level, the paper also considers alternate organizational deployment schemes } \\
\text { and properties for an off-line or spot bulk messaging capacity market, subject to technical and } \\
\text { regulatory constraints. }\end{array}$} \\
\hline \multirow{3}{*}{$\begin{array}{l}\text { Library of Congress } \\
\text { Classification } \\
(\mathrm{LCC})\end{array}$} & $5001-6182$ & Business \\
\hline & $5201-5982$ & Business Science \\
\hline & HE 9713 & Wireless Telephone \\
\hline \multirow{3}{*}{$\begin{array}{l}\text { Journal of Economic } \\
\text { Literature } \\
\text { (JEL) }\end{array}$} & M & Business Administration and Business Economics \\
\hline & L 96 & Telecommunication \\
\hline & D 44 & Auctions \\
\hline \multirow{2}{*}{$\begin{array}{l}\text { European Business Schools } \\
\text { Library Group } \\
\text { (EBSLG) }\end{array}$} & $85 \mathrm{~A}$ & Business General \\
\hline & $55 \mathrm{D}$ & Communication techniques \\
\hline \multicolumn{3}{|c|}{ Gemeenschappelijke Onderwerpsontsluiting (GOO) } \\
\hline \multirow[t]{2}{*}{ Classification GOO } & 85.00 & Bedrijfskunde, Organisatiekunde: algemeen \\
\hline & 05.42 & Telecommunicatie \\
\hline \multirow[t]{2}{*}{ Keywords GOO } & \multicolumn{2}{|c|}{ Bedrijfskunde / Bedrijfseconomie } \\
\hline & \multicolumn{2}{|c|}{ Draadloze communicatie, SMS, Telefonie Veilingen } \\
\hline Free keywords & \multicolumn{2}{|c|}{ Mobile commerce, auctions, multi-attribute auctions, SMS , EMS , MMS } \\
\hline
\end{tabular}




\title{
Auctioning Bulk Mobile Messages
}

\author{
S.Meij, L-F.Pau, E.van Heck \\ Primary contact : L-F Pau,Prof. M-Commerce email : 1pau@fbk.eur.nl \\ F1-28, Rotterdam School of Management, Erasmus University, POBox 1738 , NL \\ 3000 DR Rotterdam, Netherlands
}

\begin{abstract}
The search for enablers of continued growth of SMS traffic, as well as the take-off of the more diversified MMS message contents, open up for enterprises the potential of bulk use of mobile messaging, instead of essentially one-by-one use. In parallel, such enterprises or value added services needing mobile messaging in bulk - for spot use or for use over a prescribed period of time - want to minimize total acquisition costs, from a set of technically approved providers of messaging capacity.

This leads naturally to the evaluation of auctioning for bulk SMS or MMS messaging capacity, with the intrinsic advantages therein such as reduction in acquisition costs, allocation efficiency, and optimality. The paper shows, with extensive results as evidence from simulations carried out in the Rotterdam School of Management e-Auction room, how multi-attribute reverse auctions perform for the enterprise-buyer, as well as for the messaging capacity-sellers. We compare 1- and 5-round auctions, to show the learning effect and the benefits thereof to the various parties. The sensitivity will be reported to changes in the enterprise's and the capacity providers utilities and priorities between message attributes (such as price, size, security, and delivery delay). At the organizational level, the paper also considers alternate organizational deployment schemes and properties for an off-line or spot bulk messaging capacity market, subject to technical and regulatory constraints.
\end{abstract}

Keywords: Mobile commerce, auctions, multi-attribute auctions, SMS , EMS , MMS

Plan

1.Introduction and context

2.Theoretical framework for Mobile Messaging bulk auctions

3.Auctions in Telecommunications Service offerings

4.Bulk SMS/MMS mobile messaging reverse auction designs

5. Bulk Mobile messaging auction performance evaluation

6 Future scenarios in trading bulk mobile messaging

References

Appendices A,B 


\section{Introduction and context}

\subsection{Introduction}

When we think about auctions, fashionable e-commerce websites Auctions spring to mind. The popularity of auctions has encouraged the growth of auction support software for both buyers and sellers. These auctions usually involve a site where a seller posts items or services for sale and many bidders attempt to buy them. But in reverse auctions, one buyer usually hosts a site listing items or services it needs and asks many sellers to bid on the prices.

However, for all public telecommunications services, whether in so-called deregulated countries or in the remaining regulated ones, there is no auctioning of telecommunications service prices ; there are at best business contracts embodied in service level agreements (SLA's) between a service user and each of its mobile service operator suppliers or value-added service suppliers , and some small clearinghouses for bandwidth or some SMS capacity provided as a business service .

Operators between themselves, if they have service level agreements (SLA's) may want to auction off spare capacity for commodity capabilities such as bandwidth, emergency frequency spectrum, and possibly network management services. This auctioning is mostly telephone auctioning within a club, and only rarely have tools been developed for bandwidth pricing and auctioning (Pau (1999) ) .The difficulty is that the spare capacity is dynamic, and has itself different costing basis , and furthermore that there are high technical demands as to technical qualification of SLA quality-of-service attributes and their verification at provisioning time .

Remain so far some unregulated public value-added services, where regulators or practices would not be limiting factors. In this space, few services have enough volume and business value to warrant interoperator, or enterprise auctioning processes. And most depend then on content or on human assistance (inquiry information, reverse directory information, etc ...).

However, the class of mobile messaging (SMS, EMS and MMS) is a reasonable candidate for reverse auctions, as demand for better pricing terms than public operator mobile messaging tariffs is huge, as many business processes or services demand mobile messaging as a channel, and finally as there are less technical hurdles to be resolved.

Today, SMS's are short standardized messages with ASCII text only, with a limited number of characters, defined as part of most $2 \mathrm{G}$ standards (GSM, CDMA, DAMPS, PDC), and offered as services by public mobile operators. However, SMS services are also deregulated, so a value-added service provider (VASP) or value added resellers (VARS) created under the provisions of Virtual Mobile Operators regulation (EU) could get bids from operators to deliver bulk SMS'es to e.g. company VPN's, or could serve as a market maker between enterprises and operators. By the end of 2001, SMS traffic was about 40 Billion SMS messages/month, growing at about $40 \%$ year. 
The SMS's would also be improved to cater to the Enhanced Messaging Service (EMS) standard under 3GPP, where multimedia attachments and other fonts would be included. EMS is a standardized instance of Multimedia Messaging MMS.

MMS is an emerging messaging standard and is specified by 3GPP, and in use with a number of early $3 \mathrm{G}$ operators (3GPP1 compliant ).MMS is an evolution of traditional messaging services but goes beyond simple text and voice messaging and will allow users to send and receive messages in a whole new array of media types e.g. text, audio, images and eventually video. MMS messages can be sent between mobile terminals, between a mobile terminal and server or server initiated push to a mobile terminal.

Like SMS, EMS \& MMS may be delivered in pre-paid mode, contract or non-contract based. EMS may be delivered only to a network cell, or a group of cells. There is intended to be a special market for Mobile Instant Messages.

\subsection{Scope of the paper}

The scope of the paper is to establish the characteristics and benefits of a bulk-SMS/MMS reverse multi-attribute auction by developing two prototypes of a single-side 3-dimensional attribute reverse auction to trade bulk-SMS and MMS.

The objective of this paper can be divided into three goals:

- To develop a conceptual model and establish the characteristics of the Mobile Messaging Bulk Reverse auction ,as supported by a prototype .

- Test the performance of a multiple round auction in order to determine what kind of 3dimensional auction will lead to Pareto Optimality and Allocative Efficiency in trading bulkSMS/MMS.

- $\quad$ Define further fields of research for using reverse auctions in trading mobile messaging.

\subsection{Plan of this paper}

This paper is divided into seven sections. Section 2 will describe the theoretical background of eauctions. Not only we will focus on the various (reverse) e-auction aspects, but also a look into today's world of Telecommunication auctions will be given in order to deploy under which circumstances (reverse) auctions are successful (in telecommunications). In section three the conceptual model describes the multiple hypothesis to test and the methods to tests these hypothesis. The basis of the research project is articulated. Section four investigates the mobile messaging market, with special interest into the market of Bulk-SMS in order to characterize what the roles of the stakeholders in the e-auction are. After the fields of e-auctions and mobile messaging are discussed, the prototype will be 
developed in section five. First the characteristics and parameters of the English and Multiple round auctions will be described. Consecutive the prototypes are built and described. In section 6 the results of the laboratory experiments are analyzed, in order to observe what kind of 3-dimension e-auction will lead to Pareto Optimality and Allocative Efficiency in trading bulk-SMS/MMS. After the auction is tested in a laboratory, in section 7 an insight into the future will be given by developing future scenarios for trading mobile messaging in the telecom sector. Finally, in section eight conclusions, limitations and further research are formulated.

\section{Theoretical framework for Mobile Messaging bulk auctions}

\subsection{Definitions}

- e-auction is defined as a web enabled automated auction were the communication takes place via the Internet.

-single-side indicates that the only one party will place bids.

-reverse indicates that in the auction the competition takes place between the sellers instead of the buyers. The sellers, e.g. networks operators or VARS, are actually placing the bids at the request of the buyers.

-multi-dimensional indicates that multiple parameters will determine the winner of a contract. Not only price but also other variable quality-of-service (QoS) parameters like security and quantity are part of the bid in the SMS auction. Other fixed variables in the SMS auction are delay and size. In the MMS auction the variable dimensions are formed by size, quantity and price. Fixed variables in the MMS auction are security and delay.

-bulk-SMS/MMS is defined as usage of SMS/MMS in bulk by a single buyer for the following main area's: Messaging, Mobile Commerce, Information Services, Advertisement, Entertainment, Customer Relationship Management, Mobile Marketing, Field Support,Work force management , etc...

-Pareto Optimality in a multidimensional auction means having a winning bid from which no mutually beneficial bids exist (i.e. for the bid taker and that particular bidder). Note that this not necessarily means that the bid taker's utility is maximized.

-Allocative Efficiency defines whether the winning bid is made by the most efficient bidder. Or is there a bidder who could make a feasible bid (feasible for both parties) that would improve the bid taker's utility? The latter would not be efficient. 


\subsection{Theoretical background e-auctions}

\subsubsection{Electronic Markets}

Markets play a central role in the economy, facilitating the exchange of information, goods and payments. In this process, they create economic value for buyers, sellers, market intermediaries and for society at large. This process is a form of coordinating the flow of materials or services through adjacent steps in the value added chain. Coordinating such a value chain can be done in two basic mechanisms: markets and hierarchies ${ }^{1}$. Markets coordinate the process through the dynamic process of supply and demand. Market forces determine the sales-attributes (design, price, delivery and quantity). The buyers choose the optimal of these attributes in such a transaction. This form is widely used among different individuals and firms. Hierarchies in contrast, coordinate the flow of materials trough adjacent steps by controlling and directing it at a higher level within the managerial hierarchy. Managerial decisions, not the interaction of the sales-attributes, determine how design, price, delivery and quantity are related when products from one step in the value chain are procured for the next step. The transactions costs is the main criterion to measures the performance of the mechanisms. Hierarchies were widely used for coordinating the value chain since the transaction cost were lower then in a market form. By using various information technologies in an electronic market, the transaction costs have fundamentally decreased. Therefore, Malone predicts a substantial change towards markets as a form of coordination. Furthermore, a product should have characteristics which are easily described in order to be traded electronically.

Thus a major impact of the electronic market systems is that they typically reduce the search costs buyers must pay to obtain information about the prices and product offerings in the market. Bakos ${ }^{2}$ identifies certain other characteristics as relevant to a strategic analysis of these systems, namely network externalities, technology uncertainty, switching costs, and economies of scale and scope. Recent years have seen this increase in the role of information technology in markets. Both in traditional markets and in the emergence of electronic marketplaces, such as the Internet-based auctions.

In order to analyze a market, Bakos claims that markets have three main functions:

- $\quad$ Matching buyers and sellers

- Facilitating the exchange of information, goods, services and payments associated with markets transactions

- $\quad$ Providing an institutional infrastructure, such as a legal and regulatory framework

\subsection{2 e-Auction}

\footnotetext{
${ }^{1}$ Malone, T., Yates, J., Benjamin, R., (1987), Electronic Markets and Electronic Hierarchies, Communications of the ACM, vol. 30, no. 6, June 1987

${ }^{2}$ Bakos, J. (1991), A strategic Analysis of Electronic Marketplaces, MIS Quarterly, September 1991, pp. $295-310$
} 
Another specific form of an electronic market is the electronic auction. An auction is a market institution with an explicit set of rules determining resource allocation and prices on the basis of bids from the market participants.

Online (e) auctions differ from manual auctions in several ways. First, the speed of information in eauctions is rapid, with instant communication and feedback. Second, the cost of contact among bidders is greatly reduced via the use of a knowledgeable intermediary, a third party auctioneer who introduces qualified suppliers to the buyers and vice versa, and manages the trade-processes. Also geographic and temporal convenience is increased, as asynchronous bidding is possible and bidders are able to participate from all over the world. Third, e-auctions represent a significant compression in negotiation time and preparation. Finally, the e-auction can preserve bidder anonymity, by not allowing the participants in the auction to know their identity or number of participants in the auction process.

\subsubsection{Type of auctions}

According to Van Heck and Vervest three types of web-based auctions can be distinguished. In webbased sales auctions one seller offers to as many buyers as allowed into the auction. In a web-based procurement auction one buyer tenders his procurement needs via the web-auction. In this type of auction, multi criteria like price, quality, delivery time are part of the bid. In the last auction type, webbased many-to-many auctions, many suppliers offer to many potential buyers. 


\subsubsection{Basic auction mechanisms}

Several mechanisms are developed to coordinate the bidding processes. Four basic types of auctions are widely used and analyzed: the ascending-bid auction (also called the open, oral or English auction), the descending-bid auction (used in the sale of flowers in the Netherlands and so called the Dutch auction), the first-price sealed-bid auction and the second-price sealed-bid auction (also called the Vickrey auction).

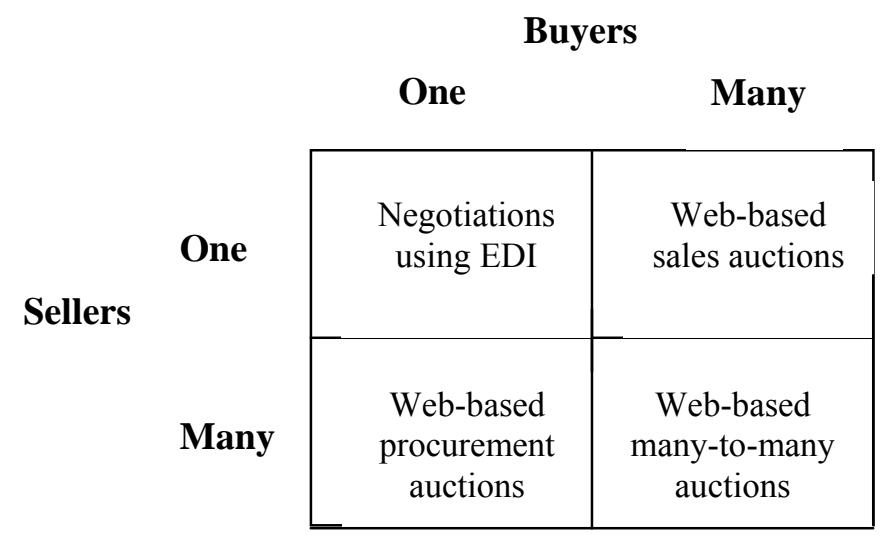

Figure 1 The use of auctions in electronic commerce

\section{English auction}

In the ascending auction, the price is successively raised until one bidder remains, and that bidder wins the object at the final price. This auction can be run by having the seller announce prices, or by having the bidders call out prices themselves, or by having bids submitted electronically with the best current bid posted. In the model most commonly used by auction theorists the price rises continuously while bidders gradually quit the auction. Bidders observe when their competitors quit, and once someone quits, she is not left in. There is no possibility for one bidder to pre-empt the process by making a large 'jump-bid'.

There are two options in which an English auction can end. This can be after a pre-defined (fixed) point in time or at a moment where after there haven't been any bids for a certain time. Ending an English auction on a pre-defined point in time has as main advantage that the duration of the auction is fixed. The bidders know on forehand how long they have to 'attend' at the auction. On the other hand it enhances the danger of 'sniping" 3 . Bidders could make a bid just before the ending of the auction, cause of the time-constraint the other bidders couldn't react to this bid. When the other option is used, a bid is accepted when there haven't been any bids for a certain time (once, twice.......sold). The major disadvantage of this systems is that beforehand the duration of the auction is unknown.

\footnotetext{
${ }^{3}$ Lucking-Reiley, D., (1999), Auctions on the Internet: What's Being Auctioned, and How?, Department of Economics, Vanderbilt University, Nashville
} 


\section{Dutch auction}

The descending Dutch auction works exactly in the opposite way of the English auction: the auctioneer starts at a very high price, and then lowers the price continuously. The first bidder who calls out that she will accept the current price wins the object at that price. The advantage of this auction mechanism is the enormous speed in which an auction can be run. Hence the us of this auction mechanism in the case of perishable goods or auctions whereby in a short time the buyer would like to buy a lot of different products.

\section{First-price sealed-bid}

In the first-price sealed-bid auction each bidder independently submits a single bid, without seeing others' bids, and the object is sold to the bidder who makes the highest bid. The winners pays her bid (that is, the price is the highest or 'first' price bid). This type of auction is mainly used in tenders. There is a possibility to run this auction over several rounds where after every round the winner is announced. Bidders have the possibility to make a new bid. Compared to the Dutch and English auction the main difference is the information structure. Bidders have to make their bids (almost) without information of the other bidders' bids.

\section{Second-price sealed-bid}

In the second-price sealed-bid auction, each bidder independently submits a single bid, without seeing others' bids, and the object is sold to the bidder who makes the highest bid. However, the price she pays is the second-highest bidder's bid, or 'second price'. This auction is sometimes called a Vickrey auction after William Vickrey, who wrote the seminal paper on the auctions ${ }^{4}$. According to Vikcrey this type of auction delivers the same outcome for the seller as the English auction time; the Revenue Equivalence Theorem.

Besides these four key-auction mechanisms there are many alternative mechanisms developed. These are all based on the four key-auction mechanisms and only differ in secondarily characteristics. These are often developed for specialized markets or situations.

\subsubsection{Relative performance of auction mechanisms}

Nobel price winner Vickrey ${ }^{5}$ studied three of the basic auction mechanisms: the English auction, the Dutch auction and the Sealed bid auction. Vickrey shows that under certain conditions:

- The strategically equivalence of the English and the Second-price auction.

\footnotetext{
${ }^{4}$ Strecker, S., (2001), Electronic Negotiations, A memo on Taxonomy, Terminology and an Introduction to Literature, Information Management and Systems, University Karlsruhe, Karlsruhe ${ }^{5}$ Vickrey, W. (1961), Counterspeculation, Auctions, and Competitive Sealed Tenders, Journal of Finance, 16, 8-37
} 
- The strategically equivalence of the Dutch and First-price auction.

- All four basic auction mechanisms lead to Pareto efficiency allocation and generate the same expected value.

- Given that bidders are risk-averse, Dutch auctions generate a higher expected value than an English auction.

So according to the Revenue Equivalence Theorem the four basic auction types generate the same expected value for the sellers in the Nash-equilibrium ${ }^{6}$. The Nash-equilibrium describes a situation where none of the bidders can gain an advantage by changing of strategy, given an unchanged strategy of the other bidders. The choice for an specific auction mechanism has therefore no influence on the expected revenue of the bid-taker (seller).

Furthermore, the article of Bulow and Klemperer compares traditional negotiating with auctioning. They were especially interested in the expected price formation, which learned that:

- Normal auctions lead to a higher prices than negotiating

- Reverse auctions lead to lower prices than negotiating

In both cases the auction increases the competitiveness and transparency. In a normal auction this takes place among the buyers, in the reverse auction the increase takes place among the suppliers. The increased competition among the buyers has a price gaining effect, where as the same competition between the suppliers has a decreasing effect on price.

\subsection{Reverse Auctions}

In a sales auction there are typically more potential buyers who have to compete among each other to finally close a deal with one sales party. In procurement auction on the contrary, competition takes place among the different sellers to eventually deliver to one buyer. This type of auction, where the competition takes place among the sellers, is called a reverse auction (also called tender of procurement auction). The idea behind this type of auction is to change the traditional seller-driven market into a buyer-driven market. This also means that the search costs of the buyer are transferred to the seller.

A stimulus for the use of reverse auctions is the potential process savings associated with them. They typical purchasing process involving mailing 'request for proposals' to potential buyers, followed by printed responses, manual reviews of the proposals and ongoing negotiations. The average length of this process is several weeks. An online reverse auction dramatically reduces the negotiation time, whereby the bidding can occur over a span of a few hours.

The auctions mechanisms discussed in paragraph 2.2.4 are also suitable in a reverse auction. Some of their characteristics will slightly change, therefore they are again discussed separately.

\footnotetext{
${ }^{6}$ Bulow, J., Klemperer, P., (1996), Auctions versus Negotiations, American Economic Review, 86, pp. 180-194
} 


\section{English auction}

When an English auction is 'reversed' the price in the auction will keep dropping. The auction starts at a high price level where after the bidders can place their bid on a decreasing price, until there is one bidder left, the winner. This market form has the advantage that it reveals market information during the auction process. Hence, a seller who has made a 'mistake' can still make a new bid in order to win the auction. The disadvantage of this type is besides the time needed to run this auction also the danger of 'sniping'.

\section{Dutch auction}

A reverse Dutch auction is an auction whereby the price doesn't drop but rises, like a normal English auction. The auction starts at a low price level, the price automatically increases and the first bidder who bids is the winner and has sold his products. The other sellers have waited to long and won't sell to this buyer. This method has the advantage that it is quite fast. A drawback is the lack of market information during the auction. The information is revealed when the transaction is done, locking out any anticipations on the information.

\section{Sealed-bid}

In an sealed bid auction the bids are not made public. The multiple bidders bid to a certain lot against a certain price. The bidder with the best bid wins the contract. The reverse aspect doesn't really change the characteristics of these auction types. 


\subsection{Multidimensional Auctions}

\subsubsection{Multidimensional auction characteristics}

In most auctions only one variable is put up for auction, namely price. A well defined product with fixed characteristics is offered for sale. The only negotiable dimension is therefore price. However, in the reverse auction case, the bid-taker is much more likely to solicit bids that are based on more than just price alone. Bidders now would not submit a one-dimensional bid of just price, but instead submit a bid consisting of a vector of characteristics such as price, quantity, quality, delivery time and warranty. The multidimensional auction could also give answer to the problem of the dropping prices because of strong price-competition, which is negative for the sellers. Since the bid is not only made out of price, the other dimensions play a role which could have a price-gaining effect. This effect has advantages for both sellers (they could earn a better price for their product) and buyers. The bids will probably be more diverse and new combinations of the dimensions will occur which can better match the buyers demand.

Little research is done about the use of the basic auction mechanisms in a multidimensional setting. Che looked at three different auction mechanisms (first priced sealed bid, second price sealed bid and second preferred offer) for two-dimensional auctions (on price and quality), based on actual practices at the US Department of Defense. He showed that under certain circumstances the three investigated mechanisms yield the same expected revenue and that in all circumstances, quality is either undervalued or overvalued from the buyers' point of view. In his analysis, he assumed that the costs of the bidding firms were independent. Branco extended Che's analysis by deriving an optimal auction mechanism for the more realistic case when the bidding firm's costs are correlated. In additional to most one-stage auctions he argued for the use of two-stage mechanisms. In the two-stage mechanisms one supplier is selected by analyzing all bids with the consumer surplus function. This elects one supplier for a second round or bargaining with the procurer.

The information feedback given during an auction has a influence on performance. Koppius investigated this role of information feedback given during the auction process in a multidimensional auction. He described various feedback policies and analyzed the impact on the performance on the auction mechanism using the criteria of efficiency and optimality. Results of his laboratory experiments learned that an unrestricted information architecture (i.e. more information revealed about the state of competition and the bid taker's preferences) increases the optimality and efficiency of the multidimensional auction. Also auctioning over 4 rounds instead of 2 improves the optimality of the auction, but has no overall effect on efficiency.

\subsubsection{Measuring performance in a multidimensional auction}


To analyze the effects of the different auction set-ups on the performance of the auction mechanism, criteria is needed by which to judge market performance, as this can be measured in different ways. Two measures that are particularly relevant are:

- $\quad$ Allocative efficiency

- Pareto optimality

Pareto optimality in a multidimensional auction is measured at the dyad level of (winning) bidder-bid taker. A (winning) bid is Pareto optimal if no feasible bid can be made which is a Pareto improvement, i.e. no mutually beneficial bids exist for the bid taker and that particular bidder. This does not necessarily mean that the bid taker's utility is maximized. Allocative efficiency is achieved when the most efficient bidder makes the actual winning bid. In standard one-dimensional auctions, Allocative efficiency is achieved when the bidder with the highest valuation wins the auction. In the reverse auction under consideration here, it means that the bidder with the lowest cost structure wins the auction. So a multidimensional auction is efficient if, given a winning bid, there does not exist a different bidder who could make a feasible bid (feasible for both parties) that would improve the bidtakers utility. Loosely speaking, efficiency ensures that the eventual trade occurs between the 'right' trading partners, optimality ensures that the total surplus of that trade is maximized. Note that in a multidimensional auction, a winning bid can be Pareto optimal, yet at the same time not Allocative efficient en vice versa. An optimal, inefficient winning bid can occur when the winning bidder has Pareto-optimized his own bid relative to the bid taker's utility, yet there may be a different bidder that could outbid him (Allocative inefficiency), but that bidder has not made such a bid. A non-Pareto optimal, Allocative efficient winning bid can occur when there are no bidders that outbid the current highest bidder (Allocative efficient), yet his current bid could be Pareto-improved upon by himself.

Market performance is thus measured by Allocative efficiency and Pareto optimality. In the laboratory experiment in this thesis two measures of efficiency are used in analogy to Koppius' study: EFF, which is a binary variable indicating whether or not the winning bid is efficient and TOTEFF, which indicates the distance from the winning bid to the efficient bid. For Pareto optimality, the main measures are PARETO and NPARETO. PARETO is a binary variable indicating whether or not the bid is Pareto optimal, i.e. whether or not there existed a bid that would have made at least one party better off without making the other party worse off. NPARETO is the number of Pareto improving bids that existed at the end of the auction. Two additional measures, PARPLUS and NPARETO respectively, expect that the requirement is that now both parties have to be strictly better off, i.e. a higher profit for the bidder and a higher utility for the bid taker.

\subsection{Design of an auction}

When we focus on the auction design multiple details are important. Kambil and Van Heck came up with the following relevant details:

- Number of bidders and bid-takers

- Number of auction able units 
- Order of offering

- Stock during auction

- Length and time of the auction

- Auction speed

- Minimum bid and reserve price

- Ratio fixed costs - total auction price

- Information architecture

\section{Auctions in Telecommunications Service offerings}

\subsection{Auctions in telecommunication services and SLA's}

By telecommunications service offerings are meant actual billable managed services by an operator or value added service operator ,as opposed to ,say bandwidth or leased lines, as researched by Chiu, and Pau $(1999,2000)$,etc ..

In addition to the need of standardized contracts, McKnight studied the use of Service Level Agreements (SLA's) in the trading of broadband access. He claims that the economic rule of SLA's is to lower the transaction costs associated with contracting costs associated with contracting for a particular quality of service and to allocate the risks and costs of producing and consuming the service. Such contracts are especially important in markets for intangible goods such as communication services which present a more complex challenge for trade than do tangible goods.

First, tangible goods are storable which means the production and consumption can be separated in time. This often simplifies the evaluation and verification of product attributes and the operation of anonymous markets. Second, much of the value of the service contract may be vested in the right (but not the obligation) to consume. This creates incentives to statistically aggregate customer demand to more efficiently utilize available capacity. Third, the service contract for the exchange of intangible goods establish rights over the transaction. These property rights then can be traded and give rise to other derivative markets that can help shift risk and allocate costs. Hence, SLA's provide the basis for establishing the needed QoS guarantees (i.e. the customer will be provided with a verifiable level of service).

When selecting a specific auctioning mechanism multiple merits should be considered. An important factor in Mobile messaging auctioning is speed. On the long run trading of mobile messages will take place via real-time auctions. So given this real-time character, speed is quite important.

Another issue next to speed in Mobile messaging auctions, is the price formation. One of the objectives of auctioning mobile messaging is price reduction. 


\subsection{Mobile messaging auction experimental designs}

Therefore two experiments have been set-up with two types of multiple-round auctions:

- $\quad$ One round (first round sealed bid)

- $\quad$ Five rounds

The first type stresses the aspect of speed. The second one rather focuses on the optimal price formation, and lays a bit closer to the traditional way of today's bilateral negotiating behavior. Hence, stimulating the adaptability by the stakeholders.

Combing the variation of number of rounds in the auction and the performance measures (as discussed in paragraph 2.4.2) leads to the following hypotheses which were tested and performance evaluated

\section{Hypothesis regarding Allocative Efficiency}

Hypothesis 1 A 5-round auction will improve average efficiency $\left(\mathrm{EFF}_{5}>\mathrm{EFF}_{1}\right)$

Hypothesis 2 The average distance between the winning bid and the efficient bid will be smaller in a 5-round auction $\left(\mathrm{TOTEFF}_{5}<\mathrm{TOTEFF}_{1}\right)$

Hypothesis 3 Average Pareto optimality will be larger in a 5-round auction

$$
\left(\text { PARETO }_{5}>\text { PERETO }_{1}\right)
$$

\section{Hypothesis regarding Pareto Optimality}

Hypothesis 4 The number of Pareto-improving alternatives will be smaller in a 5-round auction ( NPARETO $_{5}<$ NPERETO $_{1}$ )

Hypothesis 5 Average strict Pareto-optimality will be larger in a 5-round auction $\left(\right.$ PARPLUS $_{5}>$ PARPLUS $\left._{1}\right)$

Hypothesis 6 The number of strict Pareto-improving alternatives will be smaller in a 5-round auction $\left(\mathrm{NPARPLUS}_{5}<\mathrm{NPARPLUS}_{1}\right.$ )

\subsection{Mobile messaging types}

The mobile messaging market currently consists of three types of messaging:

- $\quad$ Short Messaging Service (SMS)

- $\quad$ Enhanced Messaging Service (EMS)

- $\quad$ Multimedia Messaging Service (MMS)

These three types will be discussed separately in the next three sub-paragraphs. In Table 1 the evolution of the mobile messaging is summarized. Note that both Short Messaging and Smart Messaging are members of the SMS-class. 


\begin{tabular}{|l|l|l|l|l|l|}
\hline Type & Characteristics & $\begin{array}{l}\text { Content } \\
\text { Reformatting } \\
\text { for mobile } \\
\text { necessary? }\end{array}$ & Applications & Support & $\begin{array}{l}\text { Timeframe for } \\
\text { availability }\end{array}$ \\
\hline $\begin{array}{l}\text { Short } \\
\text { Messaging }\end{array}$ & $\begin{array}{l}100-200 \\
\text { characters }\end{array}$ & Yes & $\begin{array}{l}\text { Simple person } \\
\text { to person } \\
\text { messaging }\end{array}$ & All phones & $1990 \mathrm{~s}$ \\
\hline $\begin{array}{l}\text { Smart } \\
\text { Messaging }\end{array}$ & $\begin{array}{l}\text { Simple } \\
\text { rudimentary } \\
\text { images and } \\
\text { ringtones }\end{array}$ & Yes & $\begin{array}{l}\text { Sending } \\
\text { pictures and } \\
\text { ringtones to } \\
\text { phones }\end{array}$ & $\begin{array}{l}\text { Some networks } \\
\text { and Nokia \& } \\
\text { Siemens } \\
\text { phones only }\end{array}$ & 1999 onwards \\
\hline $\begin{array}{l}\text { Enhanced } \\
\text { Messaging }\end{array}$ & $\begin{array}{l}\text { Text messages } \\
\text { plus simple } \\
\text { media formats } \\
\text { e.g. sound, } \\
\text { animation, } \\
\text { picture, text } \\
\text { formatting } \\
\text { enhancements }\end{array}$ & Yes & $\begin{array}{l}\text { Simple person } \\
\text { to person } \\
\text { messaging with } \\
\text { a visual feel }\end{array}$ & $\begin{array}{l}\text { EMS standards } \\
\text { expected to be } \\
\text { widely adopted }\end{array}$ & 2001 onwards \\
\hline $\begin{array}{l}\text { Multimedia } \\
\text { Messaging }\end{array}$ & $\begin{array}{l}\text { Messages in } \\
\text { multiple rich } \\
\text { media formats } \\
\text { e.g. video, } \\
\text { audio plus text }\end{array}$ & Sometimes & $\begin{array}{l}\text { Simple person } \\
\text { to person } \\
\text { messaging with } \\
\text { a visual feel }\end{array}$ & $\begin{array}{l}\text { MMS } \\
\text { standards } \\
\text { expected to be } \\
\text { widely adopted }\end{array}$ & 2002 onwards \\
\hline
\end{tabular}

Table 1: Evolution in mobile messaging

\subsubsection{Short Messaging Service}

The Short Messaging Service (SMS) is the ability to send and receive text messages to and from mobile phones. The text can consist of words or numbers or an alphanumeric combination. SMS was created as part of the GSM Phase 1 standard. The first message is believed to be sent in December 1992 from a personal computer to a mobile phone on the Vodafone network in the $\mathrm{UK}^{7}$. According to the Mobile Data Association, over 900 million messages were sent in the UK for the month of January alone, a $300 \%$ increase on the previous year.

\subsubsection{Bulk-SMS}

A large part of the SMS traffic today is accounted for by person-to-person communications (chat $\&$ text messaging). However, there is an increasing trend towards the use of SMS by business users, for both communications and as a bearer for delivery of various types of content. For example, Radiolinja reported that the number of users of SMS for content services increased from 16 to $24 \%$ during 2000/2001. This trend has created a demand from the user groups to purchase capacity in bulk resulting in the concept of Bulk-SMS. For example, in April 2001, Vodafone stated that for its German operation D2, nearly one-third of the data revenue, or $5 \%$ of the total comes from Bulk-SMS services. 


\subsubsection{Enhanced Messaging Service}

The Enhanced Messaging Service (EMS) is the ability to send ringtones and operator logos and other simple visual messages to EMS capable handsets. Additionally, EMS has the ability to send and receive a combination of simple media such as melodies, pictures, sounds, animations, modified text and standards text as an integrated message for display on an EMS compliant handset.

EMS is a standard developed by the Third Generation Partnership Project (3GPP) to embrace and extend the ability to send ringtones and operator logos. There are many different potential combinations of these media. For example, when an exclamation mark appears in the enhanced message, a melody could be played. A simple black and white image could be displayed along with some text and this sound effect. As such, EMS has two main applications: person to person messaging and phone personalization ${ }^{8}$.

\subsubsection{Multimedia Messaging (MMS) Service}

Multi Messaging Service (MMS) is a cross-industry standard for sending messages between mobile phones that can contain an unlimited amount of text. Users can also enhance the emotional content of their messages with multimedia content such as pictures, audio and video. Like SMS, MMS messages are composed on the phone and sent directly to the receiving phone. From the user's viewpoint, the relationship between this new standard and the hugely successful SMS is clear. MMS does everything that SMS can plus a lot more besides.

When it comes to providing MMS services, fundamentally different business models from those followed for SMS will be needed. The principal ways in which MMS changes the mobile messaging game are that:

- $\quad$ People will demand content to add to their messages

- $\quad$ MMS will need to interoperate with other messaging services

- $\quad$ Messages can vary greatly in size and content

- $\quad$ There will be a higher emotional attachment to message content

- $\quad$ Non person-to-person applications will be increasingly important.

MMS is an IP-based messaging standard, using the application and content standards that pervade the Internet. Nevertheless, MMS has been designed by $3 \mathrm{GPP}$, developed and implemented by the mobile equipment vendors, with the needs of the mobile network operators primarily in mind.

\footnotetext{
${ }^{7}$ Buckingham, S., (2001), Success 4 SMS, Mobile Streams, www.mobilestreams.com
} 


\subsection{Bulk-SMS business parties}

This Section identifies the stakeholders which either exist or could potentially participate in the business of bulk-SMS. The existing and potential market players are identified and their commercial and strategic relationships with the others in the "value web" are identified :

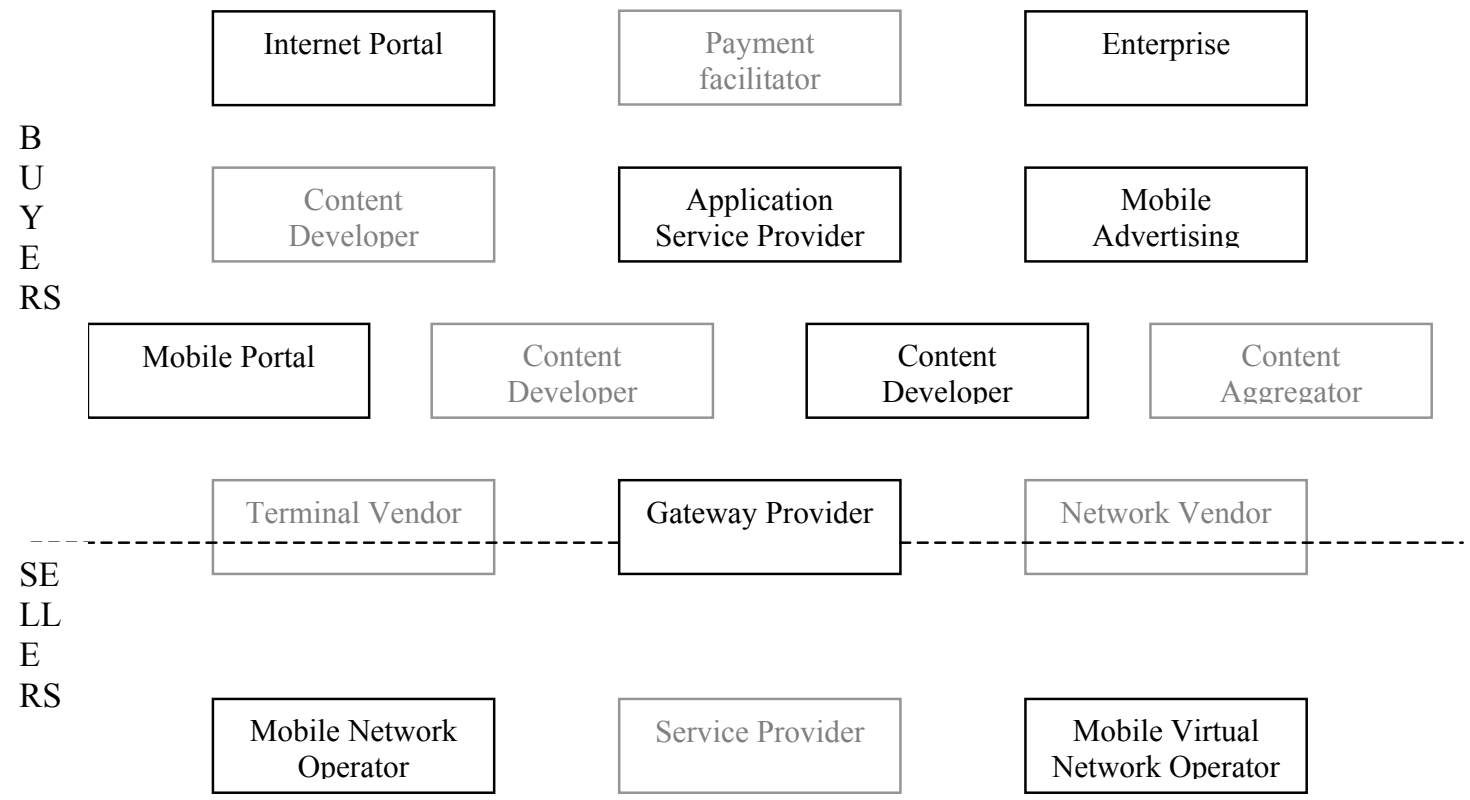

Figure 3 Bulk-SMS value web

${ }^{8}$ Buckingham, S., (2001), YES 2 EMS, An Introduction to Enhanced Mobile Messaging, Mobile Streams, www.mobilestreams.com 


\section{-Buyers}

The units in the bulk-SMS value web, identified as existing or potential buyers of bulk-SMS, are those that would use SMS in for example one of the following areas: Messaging, Mobile commerce, Information services, Advertisement Entertainment ,Field Support, Customer relationship management, Mobile marketing, Work force management,etc ....

-Sellers

All existing and potential wholesalers of SMS, have been included under the following two broad categories: Producers \& Resellers

- $\quad$ Producers of SMS: They own the SMS Center (SMSC), which they use to sell SMS capacity to resellers and users of SMS. Producers of SMS have the advantage of being able to enhance their offering with feature like interactivity, alphanumerical sender and user data header, all of which are growing in importance. They also have control over the messages being sent and received, by operating their own SMSC, placing them in a good position to guarantee service delivery. Example, Network Operators and Mobile Virtual Network Operators (MVNO's) that own an SMSC like Vodafone. Producers of SMS in Europe, i.e. network operators and MVNO's, have not placed too much emphasis on developing their SMS wholesale business due to the hassle and high costs associated with managing the business, hence they would prefer to sell to a reseller.

- $\quad$ Resellers of SMS: They do not own an SMSC but access SMS capacity from producers of SMS, by owning and operating an SMS Gateway. Their ability to offer enhancements to their basic offering, are restricted by the capabilities of the operator who's SMSC they access. However, they have the advantage over Producers of SMS of being able to enter into multiple operator agreements with multiple operators in different countries, and offer customers the convenience of an international packaged solution at a fixed price and the reliability of multiple routing options arising from access to several operators' SMSCs.

Resellers could be pure or partial resellers. The former plays the role of an intermediary between the producers and buyers of bulk-SMS. All the units positioned above them in the "value web" could be potential customers and all below are competitors, as they not only supply the gateway to access SMS capacity but also compete with the producers for the same target users. The latter invest in the SMS gateway infrastructure in the first place solely to provide a value addition to their core business and could potentially include any of the units mentioned under buyers of bulk-SMS. Since these units own the infrastructure required to access an SMSC, they could potentially also use this to resell to others, thereby acting as both customers and competitors to the pure sellers or producers of bulk-SMS. All those below could be potential competitors as they not only supply the gateway with SMS capacity but also compete with them for the same buyers. Thus, one of the interesting findings from the value web analysis is that the same players could be customers of a wholesaler of SMS and potential competitors (hybrids), indicating the need to exercise caution when analyzing their behavior in an auction. 


\subsection{Specifications of mobile messaging contracts}

In order to start auctioning the mobile messages, an insight into the product specifications is needed. First, the SMS contract attributes will be described ,then the MMS contract attributes.

\subsubsection{SMS contract attributes}

When trading bulk-SMS several product specifications are being negotiated. The most relevant contract attributes are displayed in table two. Here an distinction is made between the variable and fixed dimensions. In the bilateral negotiating process being used today to trade bulk-SMS, most of these attributes are open to negotiating. In an

\begin{tabular}{|c|c|c|}
\hline Dimensions & Attribute & Specification \\
\hline \multirow{3}{*}{$\begin{array}{c}\text { Variable } \\
\text { dimensions }\end{array}$} & Price & $\begin{array}{l}\text { Range of } 0.01 \text { to } 0.30 \text { Eurocents/SMS } \\
\text { Steps of } 0.01 \text { Eurocents }\end{array}$ \\
\hline & Security level & $\begin{array}{l}\text { Range of } 1 \text { to } 3 \text { classes according to } \\
\text { security standards } \\
\text { Steps of } 1 \text { class }\end{array}$ \\
\hline & Bulk quantity & $\begin{array}{l}\text { Min dependant of contract } \\
\text { Max } 2.000 .000 \\
\text { Steps of } 100.000\end{array}$ \\
\hline \multirow{7}{*}{$\begin{array}{l}\text { Fixed } \\
\text { dimensions }\end{array}$} & Size & 160 characters \\
\hline & Delivery delay & $\begin{array}{l}\text { Default level } \\
100 \mathrm{~ms}, 500 \mathrm{~ms}, 1 \mathrm{~s}, 5 \mathrm{~s}, 20 \mathrm{~s}\end{array}$ \\
\hline & Coverage split & $\begin{array}{l}X \% \text { of population of fixed subscribers } \\
\text { in country }\end{array}$ \\
\hline & Activation period & Within 6 hours \\
\hline & Validation of contract & Time to consume, e.g. month/week/day \\
\hline & Billing reports & Provided every week \\
\hline & Customer support & $24 \times 7$ support desk \\
\hline
\end{tabular}

Table 2 SMS contract attributes

multidimensional auction we want to fix a number of these attributes. The most costs sensitive and relevant to negotiating attributes are fixed. In the case of bulk-SMS the attributes price, security level and bulk quantity are left open for negotiating/bidding. 
Hence, the bidders in the auction not only compete on price, but also on two other variable dimensions as security level and bulk quantity. Note, that a buyer can restrict a certain variable dimension, i.e. a buyer would like to buy a minimum amount of 700.000 SMS's with any security level. The same buyer could valuate larger amounts positively (against a lower price), creating space for competition among the suppliers.

\subsubsection{MMS contract attributes}

When trading bulk-MMS the same reasoning as with SMS applies. Likewise several product specifications have to be negotiated. The most relevant contract attributes are displayed in table three. Here an distinction is made between the variable and fixed dimensions. In the bilateral negotiating process being used today to trade bulk-MMS,

\begin{tabular}{|c|c|c|}
\hline Dimensions & Attribute & Specification \\
\hline \multirow{3}{*}{$\begin{array}{c}\text { Variable } \\
\text { dimensions }\end{array}$} & Price & $\begin{array}{l}\text { Range of } 0.01 \text { to } 0.30 \text { Eurocents } \\
\text { Steps of } 0.01 \text { Eurocents }\end{array}$ \\
\hline & Size & $\begin{array}{l}\text { Min } 256 \text { characters } \\
\text { (check } 3 \text { GPP standard) } \\
\text { Max of } 10 \text { packets } \\
\text { Steps of } 1 \text { packet } \\
\text { (128 characters) }\end{array}$ \\
\hline & Bulk quantity & $\begin{array}{l}\text { Min dependant of contract } \\
\text { Max } 2.000 .000 \\
\text { Steps of } 100.000\end{array}$ \\
\hline \multirow{7}{*}{$\begin{array}{c}\text { Fixed } \\
\text { dimensions }\end{array}$} & Security level & $\begin{array}{l}\text { Default class } \\
\text { (check 3GPP standard) }\end{array}$ \\
\hline & Delivery delay & $\begin{array}{l}\text { Default level } \\
100 \mathrm{~ms}, 500 \mathrm{~ms}, 1 \mathrm{~s}, 5 \mathrm{~s}, 20 \mathrm{~s}\end{array}$ \\
\hline & Coverage split & $\begin{array}{l}\mathrm{X} \% \text { of population of fixed subscribers } \\
\text { in country }\end{array}$ \\
\hline & Activation period & Within 6 hours \\
\hline & Validation of contract & Time to consume, e.g. month/week/day \\
\hline & Billing reports & Provided every week \\
\hline & Costumer support & $24 \times 7$ support desk \\
\hline
\end{tabular}

Table 3 MMS contract attributes

most of these attributes are open to negotiating. In a multidimensional auction we want to fix a number of these attributes. The most costs sensitive and relevant to negotiating attributes are fixed. In the case of bulk-MMS the attributes price, security level and bulk quantity are left open for negotiating/bidding. Hence, the bidders in the auction not only compete on price, but also on two other variable dimensions as size and bulk quantity. Note, that a buyer can restrict a certain variable dimension, i.e. a buyer would 
like to buy a minimum amount of 800.000 MMS's with a minimum size of 3 packets. The same buyer could value larger amounts positively (against a lower price), creating space for competition among the suppliers.

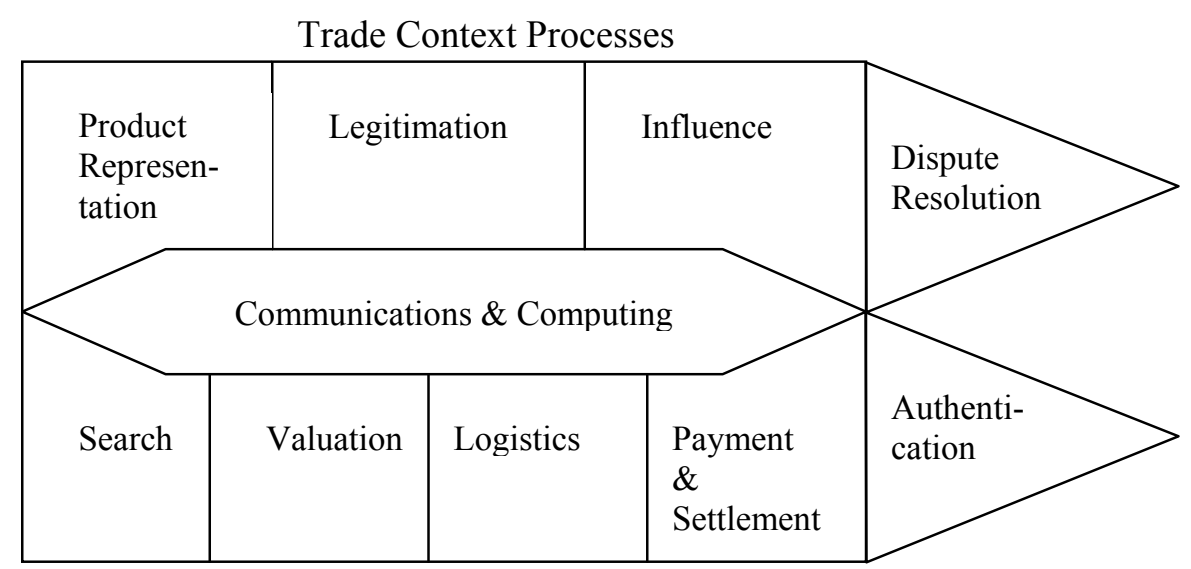

Basic Trade Processes

Figure 4 Exchange Processes 


\subsection{Mobile messaging market}

Mobile messaging exchanges represent unfamiliar territory for both buyers and sellers of mobile messaging capacity. Traditional methods to conduct business transactions are ways of the past. So what lies ahead for capacity producers, resellers and hybrids. A 'good' (as described in chapter 3) exchange promotes economic efficiency and it provides pricing signals for intelligent business planning. Additionally, mobile messaging exchanges can provide stability as well as suitable mechanisms to enable financial risk management. The impact for the stakeholders in the mobile messaging market is as follows:

- Capacity providers A capacity builder may want to sell forward contracts on their capacity to guarantee a steady stream of revenue. They can also protect themselves against severe price drops by the intelligent use of mobile messaging financial instruments. Selling forwards and option contracts allows a capacity provider to bring its network over-capacity on line in a financially secured manner. (the proceeds from selling such contracts provides the necessary capital as well as demand signal to buy the SMSC).

- Hybrids They can anonymously sell excess capacity on the spot market, enabling them to offload (quasi-instantaneously, as opposed to months of delay without an exchange mechanism) capacity that they would not use. Anonymity gives them protection against 'cannibalization' of their branded services, without diluting their market segmentation and branding promotional campaigns. They can also purchase certain capacity which is not covered by their existing portfolio, to be re-branded to quickly expand their portfolio.

- Resellers They can now purchase capacity at the market price without fear of price discrimination, particularly for small players. They can concentrate on defining products and applications with their knowledge of specific market sand special customer demands. The anonymity of the exchange market also allows these resellers to re-brand purchased capacity to capture market niche and to promote brand identity. Their increased participation will ensure the growth of capacity demand, and thus the growth of the industry.

- End customers Participation of more resellers ensures product innovation and price competition. Standard economic theory suggests that increased alternatives will improve consumer surplus simply due to enlarged subscriber set and increased competition.

- Telecommunications industry An exchange market facilitates multi-lateral and anonymity transactions. It also eliminates layers of intermediaries. This efficiency benefits traditional players in this industry. Mobile messaging exchanges also encourage the participation of many more innovative (and smaller) resellers without fear of being disadvantaged of their (small) size. The net result will be an increased number of resellers with the corresponding increase in capacity demand. This demand growth will help narrow the current supply-demand gap, which could stabilize the falling price of capacity, welcome news for capacity providers. 
But how can the benefits of the auction be captured? Similar to any commodity markets, appropriate risk management tool is required to intelligently participate in such a market. A good risk management tool should have the following characteristics:

1. It will incorporate the risk preference of the decision-maker in the planning of messaging capacity need and/or capacity building, in the presence of supply-demand uncertainties.

2. It will use sound financial/economic theory to provide consistent pricing guideline so that risk-free profit is not allowed.

3. It will allow user to dynamically update her portfolio as situation changes.

4. It will provide data tracking/analysis capability to model the dynamics of the price fluctuation process.

Standard financial derivative pricing models (such as the Black-Scholes option pricing formula) are not appropriate because of the distinct 'no-arbitrage' principles (unique to telecom capacity), in addition to the non-storability nature of mobile messaging capacity. 


\section{Bulk SMS/MMS mobile messaging reverse auction designs}

\subsection{Introduction}

The parameters and characteristics of the e-auction will be described. Then we will focus even more on the behavior of the bidder and bid takers by describing their utility functions which will simulate their costs structure, reflecting their bidding behavior. Next are described the multi-unit auction and the multiple round auction. Now that most characteristics and parameters of the auction are known, the specific design of the auction can be given ..

\subsection{Characteristics of the mobile messaging auction prototype}

In this research project two prototypes were built to analyze the behavior of one bid-taker and four bidders in a multiple round reverse SMS and MMS auction. This will represent an average bidding process and will give sufficient data to analyze the trading process and to measure the performance of the auctions.

The behaviors of the bidder and bid takers are simulated with utility functions. These utility functions will simulate the bid takers and bidders costs structure, reflecting their behavior in the auction. To generalize the results, we can use utility functions which are strictly conceptual. In the auction we can classify the behavior into certain types.

\begin{tabular}{ccc}
\hline Type & Size & Quantity \\
\hline I & $>$ & $>$ \\
II & $>$ & $<$ \\
III & $<$ & $>$ \\
IV & $<$ & $<$ \\
\hline
\end{tabular}

Table 4: Behavior in MMS auction

The bidders can only bid on the three dimensions, whereby price is a trade-off is of size and quantity. Table 4 represents the behavior in the auction, i.e. type I bidders have a competitive advantage in delivering MMS's with large size's and high quantities resulting in a relative low price in this segment.

\begin{tabular}{ccc}
\hline Type & Security & Quantity \\
\hline I & $>$ & $>$ \\
II & $>$ & $<$ \\
III & $<$ & $>$ \\
IV & $<$ & $<$ \\
\hline
\end{tabular}

Table 5: Behavior in SMS auction 
Table 5 represents the same segmentation for the SMS auction. Here the price is a trade-off of security and quantity. The bid takers behavior can likewise the behavior of bidders be represented. One bid taker can valuate a bid with a low security standard and in large quantities relatively positive, a type III bid taker. In the prototype the bidders and bid takers utility curves will be formulated considering these conceptual modeling rules. Thus the utility function parameters will be chosen such that each bidder has a comparative advantage in a different region of the bid space to partially model a realistic setting of bidder heterogeneity.

\subsection{Utility functions of bid-taker and bidder}

Making a bid in an auction is mainly dependent of the underlying costs structure and valuation of the bidder. Equivalent is the selection of the most desired bid by the bid-taker. Therefore utility functions of both bid-taker and bidder have to be made. In order to achieve the desired bidder heterogeneity, the utility functions will be conceptually modeled as described in the previous paragraph. The three dimensions in the SMS auction, namely price, security and quantity are the accountable factors. In the MMS auction these dimensions are price, size and quantity.

\subsubsection{Bid-taker utility function}

The costs structure of the bid-taker is dependant of the following:

- $\quad$ price contract + provisioning terminals to subscribers

- $\quad$ amortization terminals during contract

- $\quad$ fixed service/subscription price (constant)

Revenue elements of the MMS/SMS's are discussed in chapter four, and can be divided into three categories:

- value internal communication

- $\quad$ value communication to customers

- $\quad$ value operations

These categories can demand divergent waging of the three dimensions in their scoring rule.

\subsubsection{Bid-taker SMS utility function}

In the SMS trading experiment the number of dimensions is set to 3 , more specific price $p$, security $s$ and quantity $q$, so $b_{s m s}=(s, q, p)$. The constraints regarding feasible bid region are for both the bidtaker and all bidders identical:

$\left(1 \mathrm{a}_{\text {sms }}\right) 1 \leq$ security $\leq 3$ Classes

$\left(1 a_{\text {sms }}\right) 200.000 \leq$ quantity $\leq 3.000 .000$ SMS's 
$\left(1 \mathrm{a}_{\text {sms }}\right) 1 \leq$ price $\leq 30$ Eurocent

Note that the minimum quantity and or security is depended on the minimum quantity of the traded contract.

The bid-taker's utility functions have the following general form:

$\left(2_{\text {sms }}\right) U\left(b_{s m s}\right)=v_{1} e^{-s}+v_{2} e^{-q}-p^{2}$

In the prototype several different utility functions are made to evaluate a bid. The parameters $\mathrm{v}_{1}$ en $\mathrm{v}_{2}$ will be varied in each auction to model tradeoffs that particular buyer/bid-taker would made between security, quantity and price, see table 8 . Both $v_{l}$ en $v_{2}$ are values chosen such way, to insure that $U(b)$ represents the valuation a bid-taker would make of a specific bid. Furthermore, the formula describes the behavior of price, i.e. bids with lower price are ceteris paribus better for the bid-taker. Higher quantities or security classes are according to the valuation of the bid-taker, $U(b)$, either valued positively or negatively. So one bid-taker could value higher offered quantities and better security class positively.

\subsubsection{Bid-taker MMS utility function}

In the MMS trading experiment the number of dimensions is also set to 3, more specific price $p$, size $s$ and quantity $q$, so $b_{m m s}=(s, q, p)$. The constraints regarding feasible bid regions are for both the bidtaker and all bidders identical:

$\left(1 \mathrm{a}_{\mathrm{mms}}\right) 1 \leq$ size $\leq 10 \times 128$ packets

$\left(1 \mathrm{a}_{\mathrm{mms}}\right) 200.000 \leq$ quantity $\leq 3.000 .000 \mathrm{MMS}$ 's

$\left(1 \mathrm{a}_{\mathrm{mms}}\right) 1 \leq$ price $\leq 30$ Eurocent

Note that the minimum quantity and/or size is depended of the minimum quantity of the traded contract.

The bid-taker's utility functions have the following general form:

$\left(2_{\mathrm{mms}}\right) U\left(b_{m m s}\right)=v_{l} e^{-s}+v_{2} e^{-q}-p^{2}$

In the prototype several different utility functions are made to evaluate a bid. The parameters $\mathrm{v}_{1}$ en $\mathrm{v}_{2}$ will be varied in each auction to model tradeoffs that particular buyer/bid-taker would made between size, quantity and price, see table 7 . Both $v_{l}$ en $v_{2}$ are values chosen such way, to insure that $U(b)$ represents the valuation a bid-taker would make of a specific bid. Furthermore, the formula describes the behavior of price, i.e. bids with lower price are ceteris paribus better for the bid-taker. Higher quantities or sizes are according to the valuation of the bid-taker, $U(b)$, either valued positively or negatively. So one bid-taker could value higher offered quantities and better security class positively. 


\subsubsection{Bidders utility function}

The bid of the operators is likewise dependent of their costs structure, which is divided into:

- linear amortization costs of transmission infrastructure

- $\quad$ operating costs of billing

○ proportional to number of SMS/MMS

- amortization billing system during time of contract

- $\quad$ customer support (linked to number of customers)

- $\quad$ profit margin (proportional to revenue of contract)

Next to the above mentioned costs elements the bid of an operator is also dependent of their network load, capacity and sales. The utility functions in the prototype focus only on the three direct dimensions. They are in the case of SMS, security, price and quantity, and in the MMS experiment size, price and quantity.

The profit (utility) function for bidder $i$ is:

(3) $R_{i}(s, q, p)=p_{i}-f_{i}\left(s_{i}, q_{i}\right)$

In this profit function, $p_{i}$ indicates the price bid by bidder $i$ and $f_{i}\left(s_{i}, q_{i}\right)$ indicates the production costs for bidder $i$ of supplying the product with attributes $s_{i}$ and $q_{i}$. The production cost function has the general form:

(4) $f_{i}\left(s_{i}, q_{i}\right)=\mathrm{a}_{1, i}-\mathrm{a}_{2, i} s_{i,}-\mathrm{a}_{3, i} s_{i}^{2}-\mathrm{a}_{4, i} q_{i}-\mathrm{a}_{5, i} q_{i}^{2}$

Each bidder will face different $\mathrm{a}_{j, i}$ to create bidder heterogeneity through different cost functions (e.g. the equivalent of private values in standard auctions). The cost function parameters will be chosen such that each bidder has a comparative advantage in a different region of the bid space to partially model a realistic setting of bidder heterogeneity, see table 7 and 8 . For instance, one bidder can have a cost advantage on delivering large quantities.

\subsection{Multi-unit auction}

The study of the mobile messaging market in chapter four learned that next to trading sec Bulk-SMS, a mix of SMS, EMS and MMS is also traded in one contract. Furthermore, a certain demand of one type could be fulfilled by several suppliers. This leads to the field of multi-unit auctions described in paragraph 2.4. In the case of a multi-unit reverse auction, multiple bidders can win with identical products. The bid-taker's demand is fulfilled with products of several bidders. An important restriction for such auctions is the similarity of products which have to be inter-changeable and identical. In the reverse auction the two methods of price setting, uniform and discriminatory pricing, are still valid. 
For simplicity reasons and the fact that this research project focuses on trading sec bulk-SMS or bulkMMS, the features of a multi-unit auction won't be taken into account and therefore will not be part of the prototype.

\subsection{Multiple round auction}

When selecting a specific auctioning mechanism multiple merits should be considered. An important factor in this experiment is speed. On the long run trading of mobile messages will take place via realtime auctions. So given this real-time character, speed is quite important. Another issue next to speed if the price formation. One of the objectives of auctioning mobile messaging is price reduction. Therefore two experiments will be set-up with two types of multiple-round auctions:

- $\quad$ One round (first round sealed bid)

- $\quad$ Five rounds

The first type stresses the aspect of speed. The second one rather focuses on the optimal price formation, and lays a bit closer to the traditional way of today's bilateral negotiating behavior. Hence, stimulating the adaptability of the stakeholders.

\subsection{Implementation of mobile messaging auction prototype}

The multidimensional auction model was implemented in a software prototype built in Commercepack, designed to be run over the Internet, needing only a browser on the client's side.It was carried out in the Rotterdam Business School e-Auction Laboratory with 6 students and 3 faculty members involved . Appendix A shows a screenshot of the bidding screen. The information feedback is shown in Appendix B.

\section{Bulk Mobile messaging auction performance evaluation}

\subsection{Measuring strict utility improvement}

The auction performance in this research was evaluated on the criteria of Pareto optimality, allocative efficiency and auction duration. However, the range of utility values (numerical) prior to auction start, based on initial bid inputs, and the final utility values for buyers and bidders based on auction outcome is also interesting. This measures the direct effect for the stakeholders of using an auction.

An additional hypothesis is modeled to test the gain in auctioning over the number of rounds. 
Hypothesis $8 \quad$ A 5 round auction will improve strict utility $\left(\operatorname{GAIN}_{5}>\mathrm{GAIN}_{1}\right)$

In order to test this hypothesis we compared the winning score and initial score, both measured in their numerical utility value, in each auction. Table 6 and 7 show the actual gain in utility value for each specific auction. 


\begin{tabular}{|c|c|c|c|c|c|c|c|c|}
\hline $\begin{array}{l}\text { m } \\
\text { x } \\
\text { o } \\
0\end{array}$ & 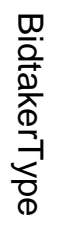 & 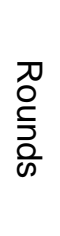 & 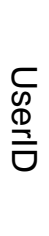 & 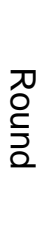 & & 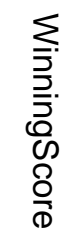 & 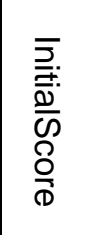 & 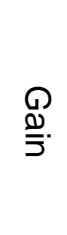 \\
\hline 1 & IV & 1 & 2 & 1 & 1 & -114 & -211 & 97 \\
\hline II & IV & 1 & 4 & 1 & 1 & -125 & -198 & 73 \\
\hline $\mathrm{I}$ & 1 & 1 & 2 & 1 & 2 & -41 & -154 & 113 \\
\hline II & I & 1 & 2 & 1 & 2 & -59 & -154 & 95 \\
\hline $\mathrm{I}$ & II & 1 & 1 & 1 & 1 & -106 & -189 & 83 \\
\hline II & II & 1 & 4 & 1 & 1 & -109 & -150 & 41 \\
\hline 1 & III & 1 & 2 & 1 & 2 & -51 & -111 & 60 \\
\hline II & III & 1 & 2 & 1 & 1 & -52 & -91 & 39 \\
\hline $\mathrm{I}$ & II & 5 & 2 & 4 & 1 & -121 & -253 & 132 \\
\hline II & II & 5 & 2 & 2 & 2 & -144 & -346 & 202 \\
\hline 1 & III & 5 & 4 & 5 & 1 & -37 & -157 & 120 \\
\hline II & III & 5 & 4 & 3 & 1 & -51 & -243 & 192 \\
\hline 1 & 1 & 5 & 3 & 2 & 2 & -51 & -124 & 73 \\
\hline II & 1 & 5 & 3 & 2 & 1 & -36 & \begin{tabular}{|c|}
-93 \\
\end{tabular} & 57 \\
\hline I & IV & 5 & 3 & 1 & 1 & -93 & -197 & 104 \\
\hline II & IV & 5 & 3 & 5 & 1 & $\begin{array}{l}-78 \\
\end{array}$ & -146 & 68 \\
\hline 1 & II & 5 & 2 & 4 & 1 & -121 & -285 & 164 \\
\hline II & II & 5 & 2 & 5 & 1 & -124 & -128 & 4 \\
\hline 1 & IV & 5 & 2 & 3 & 1 & -106 & \begin{tabular}{|l|}
-169 \\
\end{tabular} & 63 \\
\hline II & IV & 5 & 2 & 1 & 1 & -106 & -267 & 161 \\
\hline $\mathrm{I}$ & 1 & 5 & 4 & 4 & 1 & -36 & -207 & 171 \\
\hline II & 1 & 5 & 2 & 2 & 1 & -41 & -165 & 124 \\
\hline 1 & III & 5 & 4 & 5 & 1 & -36 & -246 & 210 \\
\hline II & III & 5 & 4 & 1 & 1 & -36 & $\begin{array}{l}-72 \\
\end{array}$ & 36 \\
\hline 1 & IV & 1 & 3 & 1 & 2 & -110 & -288 & 178 \\
\hline II & IV & 1 & 3 & 1 & 1 & -78 & -135 & 57 \\
\hline $\mathrm{I}$ & III & 1 & 1 & 1 & 1 & -31 & -51 & 20 \\
\hline II & III & 1 & 4 & 1 & 1 & -36 & -90 & 54 \\
\hline 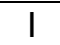 & II & 1 & 3 & 1 & 1 & -131 & -176 & 45 \\
\hline II & II & 1 & 2 & 1 & 1 & -123 & -149 & 26 \\
\hline $\mathrm{I}$ & 1 & 1 & 4 & 1 & 1 & -47 & -124 & 77 \\
\hline II & $I$ & 1 & 2 & 1 & 1 & -26 & \begin{tabular}{|l|}
-87 \\
\end{tabular} & 61 \\
\hline
\end{tabular}

Table 6: Dataset SMS auction experiments 


\begin{tabular}{|c|c|c|c|c|c|c|c|c|}
\hline $\begin{array}{l}\text { m } \\
\text { x } \\
\text { o } \\
0\end{array}$ & 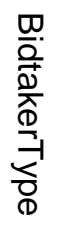 & 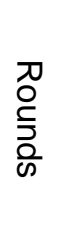 & $\begin{array}{l}\text { C } \\
\text { 足 } \\
\stackrel{\underline{Z}}{\sigma}\end{array}$ & 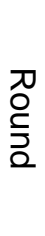 & & 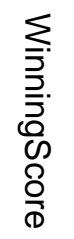 & 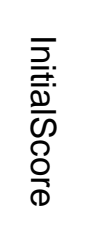 & $\begin{array}{l}\text { ه. } \\
\stackrel{\text { }}{\Xi} \text {. }\end{array}$ \\
\hline$I$ & IV & 1 & 2 & 1 & 2 & -32 & -206 & 174 \\
\hline II & IV & 1 & 2 & 1 & 1 & -19 & -152 & 133 \\
\hline $\mathrm{I}$ & $\mathrm{I}$ & 1 & 2 & 1 & 2 & 98 & 1 & 97 \\
\hline II & I & 1 & 2 & 1 & 1 & 108 & -14 & 122 \\
\hline $\mathrm{I}$ & II & 1 & 2 & 1 & 1 & $\begin{array}{l}-73 \\
\end{array}$ & -86 & 13 \\
\hline II & II & 1 & 3 & 1 & 0 & -86 & -91 & 5 \\
\hline 1 & III & 1 & 4 & 1 & 1 & 38 & -59 & 97 \\
\hline II & III & 1 & 2 & 1 & 1 & 43 & -5 & 48 \\
\hline $\mathrm{I}$ & II & 5 & 1 & 2 & 1 & -50 & -153 & 103 \\
\hline II & II & 5 & 1 & 1 & 1 & -50 & -253 & 203 \\
\hline 1 & III & 5 & 2 & 5 & 1 & -17 & -268 & 251 \\
\hline II & III & 5 & 2 & 5 & 1 & -27 & -102 & 75 \\
\hline 1 & 1 & 5 & 2 & 2 & 2 & 98 & -237 & 335 \\
\hline II & 1 & 5 & 2 & 3 & 1 & 108 & 5 & 103 \\
\hline I & IV & 5 & 2 & 3 & 1 & -17 & -193 & 176 \\
\hline II & IV & 5 & 2 & 1 & 1 & -22 & -116 & 94 \\
\hline 1 & II & 5 & 1 & 4 & 1 & -65 & -244 & 179 \\
\hline II & II & 5 & 1 & 1 & 1 & -65 & -100 & 35 \\
\hline 1 & IV & 5 & 2 & 1 & 1 & 22 & -288 & 310 \\
\hline II & IV & 5 & 2 & 5 & 2 & 9 & -152 & 161 \\
\hline $\mathrm{I}$ & 1 & 5 & 2 & 2 & 1 & 108 & -91 & 199 \\
\hline II & 1 & 5 & 3 & 1 & 0 & 108 & 5 & 103 \\
\hline I & III & 5 & 2 & 3 & 2 & 33 & -258 & 291 \\
\hline II & III & 5 & 2 & 1 & 1 & 43 & -141 & 184 \\
\hline 1 & IV & 1 & 2 & 1 & 2 & -17 & -120 & 103 \\
\hline II & IV & 1 & 2 & 1 & 1 & -17 & -104 & 87 \\
\hline $\mathrm{I}$ & III & 1 & 4 & 1 & 3 & 28 & $\begin{array}{l}-12 \\
\end{array}$ & 40 \\
\hline II & III & 1 & 4 & 1 & 1 & 53 & 3 & 50 \\
\hline 1 & II & 1 & 1 & 1 & 1 & -61 & -97 & 36 \\
\hline II & II & 1 & 1 & 1 & 1 & -50 & -70 & 20 \\
\hline $\mathrm{I}$ & I & 1 & 2 & 1 & 2 & 98 & 3 & 95 \\
\hline II & I & 1 & 3 & 1 & 1 & 108 & -6 & 114 \\
\hline
\end{tabular}

Table 7: Dataset MMS experiments

\subsection{Analysis bulk SMS auction experiment}

The behavior regarding strict utility improvement of bidder and bid-taker in the SMS experiment was analyzed using the method described in Section 2 . Because of the non-normality of the dependent variables a non-parametric test is needed for hypothesis eight. The Mann-Whitney test is used to test for differences in strict utility improvement. For the tests of hypothesis 8 a p-value of 0,05 was used throughout. The SPSS software package was used to perform the statistical analyses. 
The analysis of the strict utility improvements of the SMS auction in SPSS resulted in tables 8-10.

\begin{tabular}{rrrrrr}
\hline & ROUNDS & N & Mean & $\begin{array}{r}\text { Std. } \\
\text { Deviation }\end{array}$ & Std. Error \\
Mean
\end{tabular}

Valid $\mathrm{N}$

(listwise)

32

Table 8: Descriptive group statistics SMS bulk auction gain (Hypothesis 8)

\begin{tabular}{rrrrr}
\hline & ROUNDS & N & $\begin{array}{r}\text { Mean } \\
\text { Rank }\end{array}$ & $\begin{array}{r}\text { Sum of } \\
\text { Ranks }\end{array}$ \\
\hline GAIN & 1 & 16 & 12,75 & 204,00 \\
& 5 & 16 & 20,25 & 324,00 \\
& Total & 32 & &
\end{tabular}

Table 9: Rank statistics SMS bulk auction gain (Hypothesis 8)

\begin{tabular}{lr}
\hline & GAIN \\
\hline Mann-Whitney U & 68,000 \\
Wilcoxon W & 204,000 \\
$Z$ & $-2,262$ \\
Asymp. Sig. (2-tailed) &, 024 \\
\hline \multicolumn{2}{r}{ Table 10: Mann-Whitney statistics SMS bulk auction gain (Hypothesis 8) }
\end{tabular}

Table 8 gives the group descriptors for the gain variable in the SMS auction. We see that in a 1 round SMS auction strict utility improves with an average of 70 . The 5 round auction improves utility with an average of 118 . Table 9 and 10 show that hypothesis 8 is supported. So a 5-round SMS auction significantly improves strict utility. Correspondingly, the average gain between the winning bid and the initial bid is smaller in a 5-round SMS auction than in a 1 round auction.

\subsection{Analysis bulk MMS auction experiment}

The MMS experiment analysis is similar to the SMS analysis. Because of the non-normality of the dependent variables a non-parametric test is needed for hypothesis eight. The Mann-Whitney test is used to test for differences in strict utility improvement. For the tests of hypothesis 8 a p-value of 0,05 was used throughout. The SPSS software package was used to perform the statistical analyses. 
The analysis of the strict utility improvements in the bulk MMS auctions in SPSS resulted in tables 1113 .

\begin{tabular}{rrrrrr}
\hline & ROUNDS & N & Mean & $\begin{array}{r}\text { Std. } \\
\text { Deviation }\end{array}$ & $\begin{array}{r}\text { Std. Error } \\
\text { Mean }\end{array}$ \\
\hline GAIN & 1 & 16 & 77,13 & 48,296 & 12,074 \\
& 5 & 16 & 175,13 & 88,100 & 22,025
\end{tabular}

Valid $\mathrm{N}$ (listwise)

32

Table 11: Descriptive group statistics of bulk MMS auction gain (Hypothesis 8)

\begin{tabular}{rrrrr}
\hline & ROUNDS & $\mathrm{N}$ & $\begin{array}{r}\text { Mean } \\
\text { Rank }\end{array}$ & $\begin{array}{r}\text { Sum of } \\
\text { Ranks }\end{array}$ \\
\hline GAIN & 1 & 16 & 11,28 & 180,50 \\
& 5 & 16 & 21,72 & 347,50 \\
& Total & 32 & &
\end{tabular}

Table 12: Rank statistics of bulk MMS auction gain (Hypothesis 8)

\begin{tabular}{lr}
\hline & GAIN \\
\hline Mann-Whitney U & 44,500 \\
Wilcoxon W & 180,500 \\
Z & $-3,150$ \\
Asymp. Sig. (2-tailed) &, 002 \\
\hline
\end{tabular}

Table 13: Mann-Whitney statistics of bulk MMS auction gain (Hypothesis 8)

Table 11 gives the group descriptors for the gain variable in the MMS auction. We see that in a 1 round MMS auction, the strict utility improves with an average of 77 . The 5 round auction improves utility with an average of 175 . Table 12 and 13 show that hypothesis 8 is supported. So a 5-round MMS auction significantly improves the strict utility. Correspondingly, the average gain between the winning bid and the initial bid is smaller in a 5-round MMS auction than in a 1 round auction.

\subsection{Pareto optimality and allocative efficiency}

The results show the following for bulk SMS auctions :

-Hypothesis 1 and 2 are confirmed in the bulk SMS auction, so a 5 round SMS auction improves average efficiency . Also the average distance between the winning bid and the efficient bid is smaller in a 5 round SMS auction than in a 1 round auction 
-Hypotheses 3 to 6 are not confirmed in an bulk SMS auction . The average Pareto optimality is very high ,maybe because of the weight to the security attribute. Therefore most winning bids had the optimum security offer, reducing the Pareto improving bids .

-Hypothesis 7 is supported in the bulk SMS auction, meaning that a 1 round auction is significantly faster (33 seconds) than a 5 round action (168 seconds)

The results also show the following for bulk MMS auctions :

-Hypothesis 1 and 2 are confirmed in the bulk MMS auction ,so a 5 round MMS auction improves average efficiency ; correspondingly the average distance between the winning bid is smaller in a 5 round MMS auction than in a 1 round auction

-All of hypotheses 3 to 6 are confirmed in the bulk MMS auction,and auctioning over more rounds significantly improves the Pareto optimality in the MMS auction

-Hypothesis 7 is confirmed, and the 1 round auction only lasts $26 \mathrm{~s}$ compared to $172 \mathrm{~s}$ for the 5 round MMS auction

\subsection{Relevance of the hypotheses}

Statistical analysis of the 8 hypothesis outcomes gave more general insight in the use of auctions in the field of mobile messaging. However, some of these hypotheses are different in relevance towards the seller and buyer. Therefore, we rank these hypothesis as to domain relevance for respectively buyer and bidders in their respective business domains. So to interpret the experimental outcomes, we first interpret them without business domain priorities, and next with business domain priorities.

The theoretical analysis in Section 2 showed that in a reverse auction, information about the supplyside gives the bidder information about the state of competition among the bidders. When this type of information is more available, the more transparent the competition process becomes and the more likely it is that the most efficient bidder will actually win the auction. This performance is measured as allocative efficiency. The experiment learned that, both in the SMS and the MMS auctions, auctioning over more rounds improved the allocative efficiency. The measures of allocative efficiency is most important to the buyer. When the auction wouldn't encourage efficient behavior, the auction could be won by another party than the one with the lowest cost price. This means that the trade isn't made among the 'right' parties.

Information about the demand-side gives the bidder information about the bid-takers preferences. More precisely, about the direction in which to improve his bid. The more this type of information is available, the more fully known the bid-takers preferences and the more likely that opportunities for win-win improvements will be exploited. This type of performance is measured as Pareto optimality. Hypotheses 3,4,5 and 6 tested and verified these assumptions. Pareto optimality is relevant for both 
bidders and bid-takers. When the auction is Pareto optimal the total surplus of the trade is maximized for both parties.

Next to the performance in terms of Pareto optimality and allocative efficiency the range of utility values (numerical) prior to auction start, based on initial bid inputs, and the final utility values for buyers and bidders based on auction outcome is also interesting. This measures the direct effect for the stakeholders of using an auction. We showed that auctioning over 5 rounds instead of 1 round improves the strict utility in the SMS and MMS auctions.

\section{Future scenarios in trading bulk mobile messaging}

Considering the reverse single -sided auction of bulk mobile messages, the impact of the above results for the stakeholders in the mobile messaging area are as follows :

-Mobile network operators : they can sell excess capacity enabling them to offload to new customers rather fast, as opposed to weeks of delay without an auctioning mechanism . They can also purchase certain capacity that is not covered by their existing portofolio to be re-branded quickly

-Virtual mobile network operators : can sell excess or buy capacity as well; furthermore they may even buy the capacity from other parties than their key infrastructure supplier , and by adopting auctioning early they may win customers faster than the mobile operators .

-Users of bulk messaging : they can now purchase capacity at the best market price without fears of discrimination or dependencies, particularly for small users .Furthermore the users of bulk messaging can concentrate on the requirements from their specific field of use, in addition to driving the bi-lateral negotiations. Their increased participation will ensure the growth towards critical mass -For all : the possibility to enter private utility functions reflecting the strategy or capabilities or needs of that stakeholder

This paper did not consider the case where a trusted third party would carry out the auctions, thus adding e.g. anonymity to the bidding process. The reasons is that suppliers still have under SLA terms, to guarantee some quality of service features and to ensure technical interoperability, aspects not done efficiently by a third party focussing on auctioning .

Also, although this paper is only a first step towards real time e-auctions of bulk mobile messaging , some clues have been produced. It has been determined that a mobile messaging auction should take place in a multidimensional setting in order to make it interesting for all parties .Secondly such auctions should be run over 5 rounds instead of one round, in view of much better Pareto optimality and allocative efficiency. Nevertheless, the multiple rounds do not seem a major obstacle to optimizing the auction implementations towards execution times in the second range .

Further research will be conducted on :

-combinations of more or other bulk messaging attributes , and the adaptability of auctioning on these attributes 
-use of a risk management tool incorporating the risk preference of the buyer in the planning of messaging capacity need or build-up , in the presence of supply-demand uncertainties ;it should also allow users to update their portofolio as situations change, and give some tracking/analysis dynamics -comparison between auction derived prices and prices in the market otherwise -possibly extending the bulk MMS auction to include limited content provisioning bundles -optimize the execution for speed performance, in line with what has been done Pau (1999) on bandwidth trading

-further work on the automated SLA negotiation (has started in collaboration with the Open Group Task force on QoS ) 


\section{REFERENCES}

Bakos. Y. (1998), The Emerging Role of Electronic Marketplaces on the Internet, Communications of the ACM, August

Bakos, J. (1991), A strategic Analysis of Electronic Marketplaces, MIS Quarterly, September 1991, pp. 295-310

Barratt, M., Rosdahl, K., (2002), Exploring business-to-business marketsites, European Journal of Purchasing \& Supply Management 8, pp. 111-122

Bulow, J., Klemperer, P., (1996), Auctions versus Negotiations, American Economic Review, 86, pp. 180-194

Buckingham, S., (2001), YES 2 EMS, An Introduction to Enhanced Mobile Messaging, Mobile Streams, www.mobilestreams.com

Buckingham, S., (2001), Success 4 SMS, Mobile Streams, www.mobilestreams.com

Branco, F. (1997), The Design of Multidimensional Auctions, RAND Journal of Economics, Vol. 28, No. 1, pp. 63-81

Cason, T.N., Plott, C.R., (1996), EPA's New Emissions Trading Mechanism: A Laboratory Evaluation, Journal of Environmental Economics and Management, Vol. 30, pp 133-160

Che, Y-K., (1993) Design Competition through Multidimensional Auctions, Rand Journal of Economics, 24, 668-680

Cheliotis, G., (2000), Bandwith Trading in the Real World: Findings and Implications for Commodities Brokerage, IBM Research, Zurich

Chiu, S., Crametz, J. (1999), Taking Advantage of The Emerging Bandwith Exchange Market, RateXchange, www.ratexchange.com

Dekker, H., (2001), Wie betaalt wie?, Emerce, www.emerce.nl

Frutos, M.A, Rosenthal, R.W., (1997), On Some Myths About Sequenced Common value Auctions, Boston University, ISP Discussion Paper 7

Greenwald, A., Kephart, J., (1999), Shopbots and Pricebots, Proceedings of IJCAI, Stockholm

Grosof, B., Reeves, D., Wellman, M., (2001), Automated Negotiation from Declarative Contract Descriptions, Center for E-business, MIT Sloan School of Management, Cambridge

Hausch, D. (1986) Multi-Object Auctions: Sequential versus Simultaneous Sales, Management Science, 32, 1599-1610

Jap, S., (2001), The impact of online, reverse auctions on buyer-supplier relationships, Goizueta Business School, Emory University, Atlanta

Jin, M., Wu, S., (2001), Supply Chain Coordination in Electronic Markets: Auction and Contracting Mechanisms, Lehigh University, Bethlehem

Kambil, A., Van Heck, E., (1996), Re-engineering the Dutch Flower Auctions: A Framework for Analyzing Exchange Organizations, CRIS working paper IS-96-24, New York University Stern School, New York 
Klemperer, P., (1999), Auction Theory: A Guide to the Literature, Journal of Economic Surveys, Vol. 13(3), July, pp. 227-286

Koppius, O., (2002), Information Architecture and electronic Market Performance, Ph.D. diss., Erasmus University Rotterdam

Lucking-Reiley, D., (1999), Auctions on the Internet: What's Being Auctioned, and How?, Department of Economics, Vanderbilt University, Nashville

McAfee, R., McMillan, J., (1987), Auctions and Bidding, Journal of Economic Literature, June 1987, pp. $699-738$

Malone, T., Yates, J., Benjamin, R., (1987), Electronic Markets and Electronic Hierarchies, Communications of the ACM, vol. 30, no. 6, June 1987

McKnight, L., Lehr, W. (2000), A Broadband Access Market Framework: Towards Consumer Service Level Agreements, Center for E-business, MIT Sloan School of Management, Cambridge

Northstream, (2001) Wholesale SMS, Market Analysis, Northstream Research and Publications, www.northstream.se

Northstream, (2002) Will MMS be a success, A short analysis on Multimedia Messaging, Northstream Research and Publications, www.northstream.se

O’Hara, M. (1995), Market microstructure theory, Malden, MA, USA; Blackwell Publishers

Parente, D.,Venkataraman, R., Fizel, J.,Millet, I., (2001), B2B Online Reverse Auctions: What's New?, School of Business, Pennsylvania State

Pau,L-F (2000), A wireless 3 G tariffing and network planning tool, 3 rd Internet economics workshop, Berlin, May 2000 www.berlecon.de

Pau,L-F(1999) , A bandwidth optimization system , 2 nd Internet economics workshop , Berlin , May 1999 www.berlecon.de

Strecker, S., (2001), Electronic Negotiations, A memo on Taxonomy, Terminology and an Introduction to Literature, Information Management and Systems, University Karlsruhe, Karlsruhe

Van Heck, E., Vervest, P., (1998), How should CIOs Deal with Web-based auctions?, Communications of the ACM, Vol. 41 No. 7, pp. 99-100

Vickrey, W. (1961), Counterspeculation, Auctions, and Competitive Sealed Tenders, Journal of Finance, 16, 8-37

Wolfram, C., (1998), Strategic bidding in a multi-unit auction, RAND Journal of Economics, Vol. 29 No. 4, pp. 703-725 
Appendix A

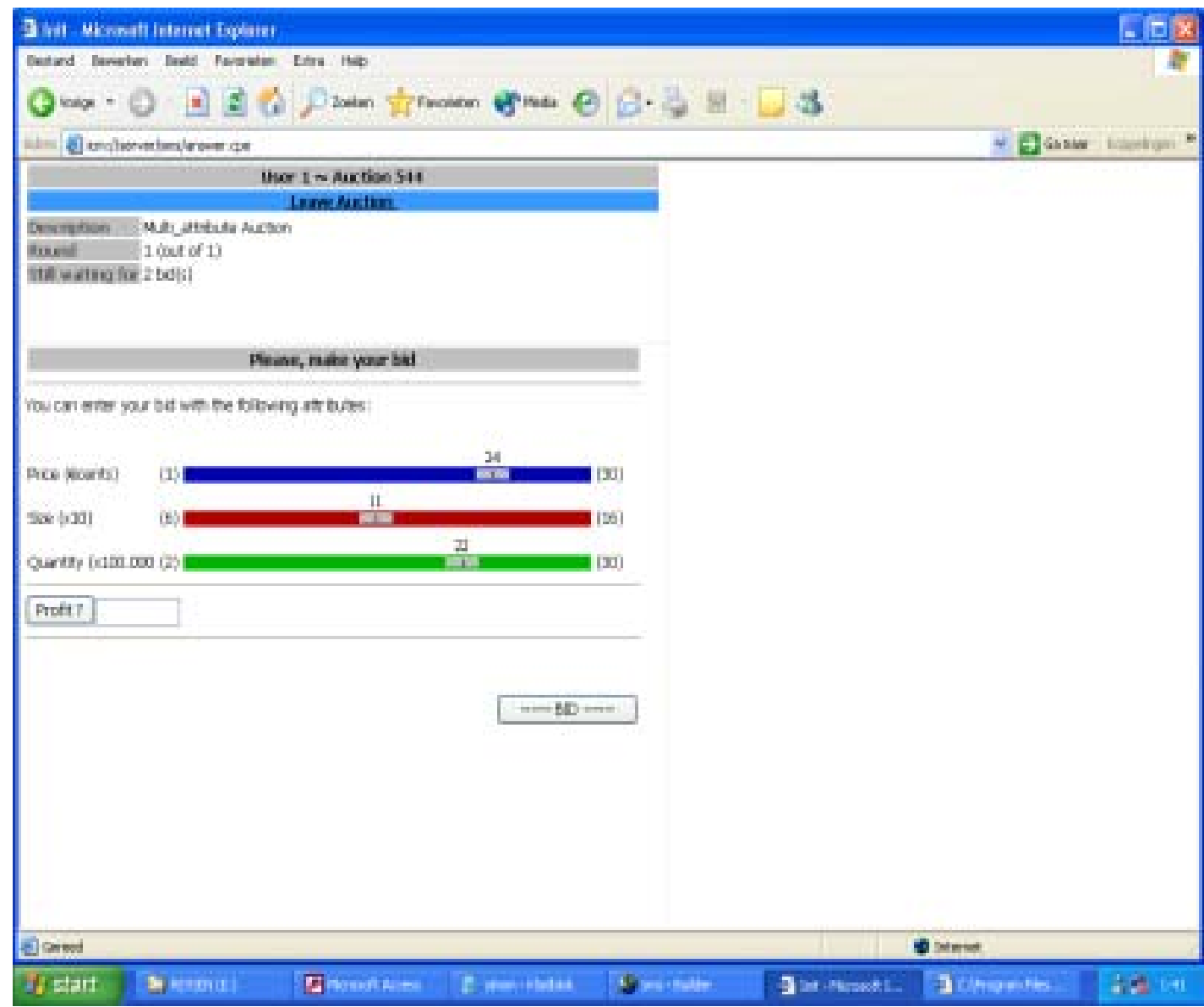

Appendix A : Example bid screen 


\section{Appendix B}

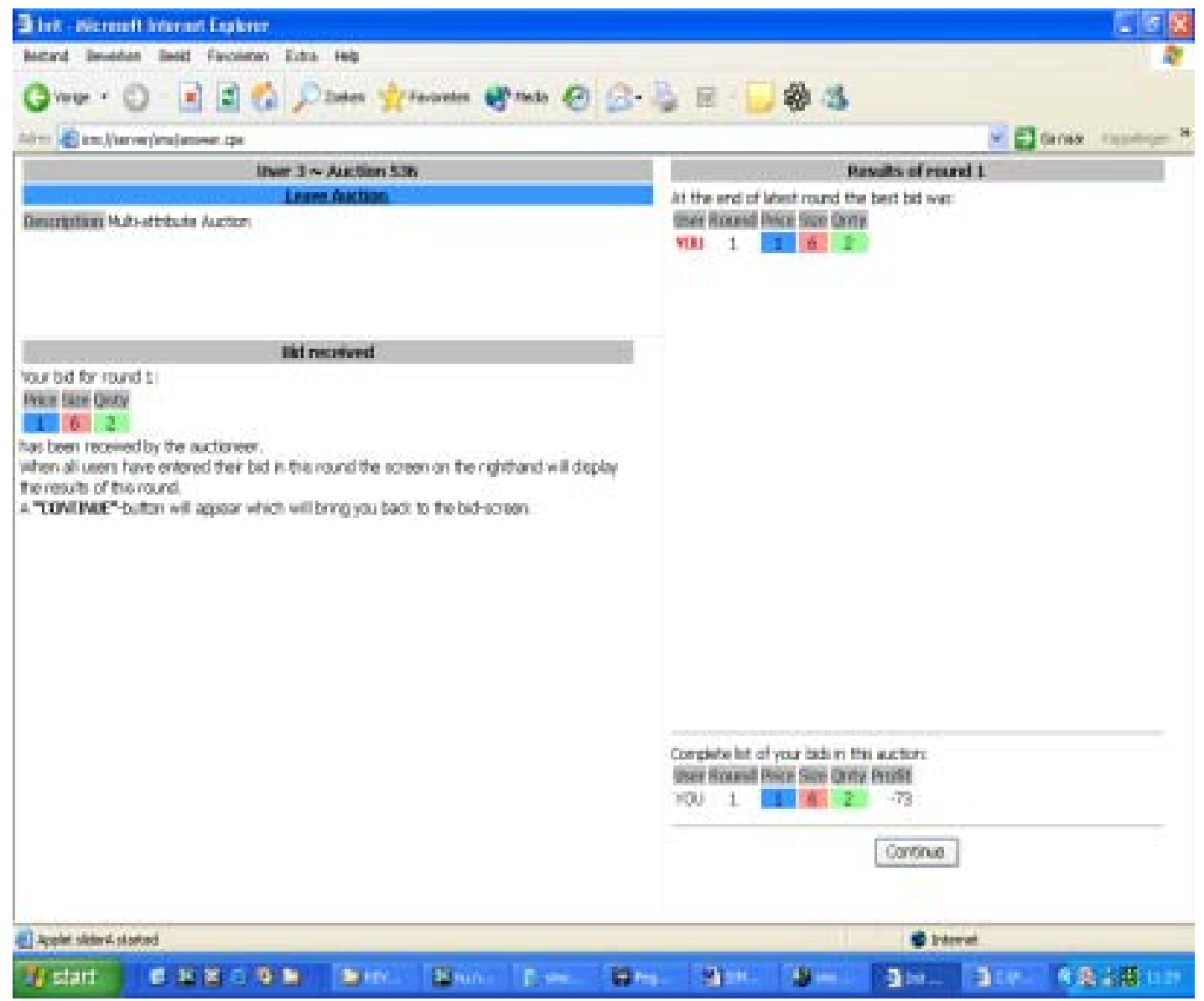

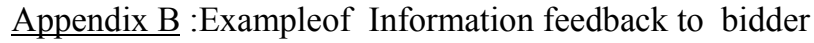




\section{About the authors:}

Simon Meij is an MBA graduate student in information management from the Rotterdam School of Management, Erasmus University.

L-F Pau is Professor of Mobile Business and M-Commerce at Rotterdam School of management, Erasmus University. He teaches in a variety of information, or technology M.B.A courses as well as in the international M.B.A program Global eManagement (GeM) . His research covers most aspects of mobile business ,as well as mobile data and Internet business models, from a user as well as a supplier perspective .He is a Fellow of IEEE, British Computer society and JSPS (Japan) .

Eric van Heck is a Professor of Electronic Markets at Erasmus University's Rotterdam School of Management, where he teaches in the international M.B.A. program and in the Global eManagement $(\mathrm{GeM})$ program. His research concentrates on the design of electronic markets and on the design of business modularization. In his research he helps companies to develop innovative, electronic auctions

\section{Corresponding author}

Prof. Dr. Louis F. Pau

Erasmus University Rotterdam

Rotterdam School of Management

PO BOX 1738

3000 DR Rotterdam

The Netherlands

Tel: +31-10-4082032

Email: L.Pau@fbk.eur.nl 


\section{Publications in the Report Series Research* in Management}

ERIM Research Program: "Business Processes, Logistics and Information Systems"

\section{3}

Project Selection Directed By Intellectual Capital Scorecards

Hennie Daniels and Bram de Jonge

ERS-2003-001-LIS

Combining expert knowledge and databases for risk management

Hennie Daniels and Han van Dissel

ERS-2003-002-LIS

Recursive Approximation of the High Dimensional max Function

Ş. İl. Birbil, S.-C. Fang, J.B.G. Frenk and S. Zhang

ERS-2003-003-LIS

Auctioning Bulk Mobile Messages

S.Meij, L-F.Pau, E.van Heck

ERS-2003-006-LIS

Induction of Ordinal Decision Trees: An MCDA Approach

Jan C. Bioch, Viara Popova

ERS-2003-008-LIS

A New Dantzig-Wolfe Reformulation And Branch-And-Price Algorithm For The Capacitated Lot Sizing Problem With Set Up Times

Zeger Degraeve, Raf Jans

ERS-2003-010-LIS

Reverse Logistics - a review of case studies

Marisa P. de Brito, Rommert Dekker, Simme D.P. Flapper

ERS-2003-012-LIS

Product Return Handling: decision-making and quantitative support

Marisa P. de Brito, M. (René) B. M. de Koster

ERS-2003-013-LIS

* A complete overview of the ERIM Report Series Research in Management:

http://www.ers.erim.eur.nl

ERIM Research Programs:

LIS Business Processes, Logistics and Information Systems

ORG Organizing for Performance

MKT Marketing

F\&A Finance and Accounting

STR Strategy and Entrepreneurship 